\title{
Construction of New Urbanization Sports Leisure Industry Circles
}

\author{
Tongchao Guo
}

\author{
Department Of Physical Education, Sichuan Agricultural University, Ya'an, Sichuan, China \\ fengtt@163.com
}

Keywords: Sports Leisure, New Pattern Urbanization, Construction.

\begin{abstract}
Over the past 30 years of reform and opening up, and the promotion of economic development and social change, sports and leisure has become Chinese important contemporary movement style, social and cultural phenomenon. In this paper, new pattern urbanization within China will continually do its own contributions to the regional development all over the world. New pattern urbanization is one product when social productive force develops to a certain degree. The paper is the positioning and comparative advantage analysis the function of sport and leisure, and points out the transformation from the city developing of sport leisure restricted from resources, creativity, environmental, industrial, system, and other conditions. Among the cities which drive to position the recreational sport theme, this paper puts forward the dual driving growth path model of creative and resource, which is the strategic choice of sport and leisure.
\end{abstract}

\section{Theoretical Introduction of New Pattern Urbanization}

New pattern urbanization refers to adhere to the people-oriented, new industrialization as the driving force balanced principle of promoting urban modernization, urban ecology. Rural urbanization can enhance the quality of urbanization and take scientific development with intensive and efficient, functional, environment-friendly, social harmony urban and rural integration. New urbanization is up to the city over the past one-sided emphasis on the pursuit of scale, spatial expansion, change the meaning of quality in order to enhance the city's prominent cultural features and modern public service center, go modern, intensive road and sustainable development, so that our town should become a pleasant place to live with a higher-quality land.

The essence of new pattern urbanization is improving the quality and content of urbanization in comparison with the traditional formulation, new urbanization more emphasis to enhance the intrinsic quality, which can promote urbanization by the emphasis on the size of the increase in the number connotation focus on quality improvement changes. Urbanization is a new manifestation of harmony and coordination "new urbanization to promote economic and social development is conducive to break the bottleneck of sustainable economic development, which is the emphasis on economic development to focus on changes in the economic and social development, urbanization over to the original dependent on industrialization, combined with changes to agricultural modernization, modern services, such as multi-power support system [1].

From the perspective of institutional reforms, the original weight of individual breakthroughs encourage cities to support rural development, and actively promote urban planning, industrial layout, infrastructure, environment, public services integration. Development of urban and rural is not reducing urban and rural living standards of the city, nor is it to destroy villages, but by the new rural construction, so that rural residents enjoy equal treatment in the urban lifestyle living environment, the development model from the point of view, which should be prominent features, relying on a variety of resources, including natural, historical and cultural, ethnic, traffic, location and other features to create development model, building professional, prominent characteristic of the town.

\section{Social Promotion Analysis of Sports Leisure Industry}

Sports leisure industry pulls effect on economic growth. From the demand perspective, the factors driving economic growth has three large pieces: consumption, investment and net exports, 
while consumption is the dominant factor driving economic growth. Because the long term, investment demand is only derived demand in consumer demand, consumer demand has not grown, so investment demand growth can't be sustained. For sustained and stable economic growth, consumer demand must be made to maintain growth. Practice has proved foreign economic, the contribution of consumer demand in the economy dominates [2].

Since the reform and opening up, China embarked on economic reform path a gradual market-oriented reform. As the economies in transition, the old post adjustment streamlined, insufficient supply of new employment opportunities, social dominance increased unemployment, coupled with long-standing presence of state-owned enterprises, such as hidden unemployment, underemployment, current employment pressure in our society suffer unprecedented labor. Sports and leisure industry is dominated by labor-intensive industries, but also lower the threshold of industrial employment. Human resource structure sports and leisure industry in general inclined to the primary skills of workers, lower training costs of labor and employment. In addition, the employment of sports and leisure industry, driven by strong, high employment multiplier.

With the development of the leisure industry to improve scientific and technological progress and the contribution rate of science and technology, increasing the living standards of residents, consumer spending and overall growth of urban and rural residents in the Engel coefficient is declining. With the increase in per capita income, the proportion of the material needs of the decline, the proportion of spiritual and cultural needs of the rise. The trends will promote a virtuous cycle of industrial structure and consumption structure. Due to the large population base of farmers, increasing farmers' income will form a greater potential for sports and leisure consumer market [3].

\section{Sports Leisure Is An important Extension of The Modern Cities}

With the development of society, land, capital, energy and other urban morphology contribute dropped sharply in the face of energy, which can be a serious shortage of commercial land under occupation conditions, the negative impact is brought about by restricting factors leading to the sustainable development of cities covered a large shadow. When some reasonable form of recreation promotes the efficiency of social production, is gradually being accepted by people, the city's main function gradually shift from production to consumption-based service, production space gradually shifted outwards, intensive development, and public leisure space and associated entertainment space, service space, space consumption tended urban centers, leisure functions become an important symbol of modern urban sustainable development [4]. Fig.1 shows the type of leisure urban development.

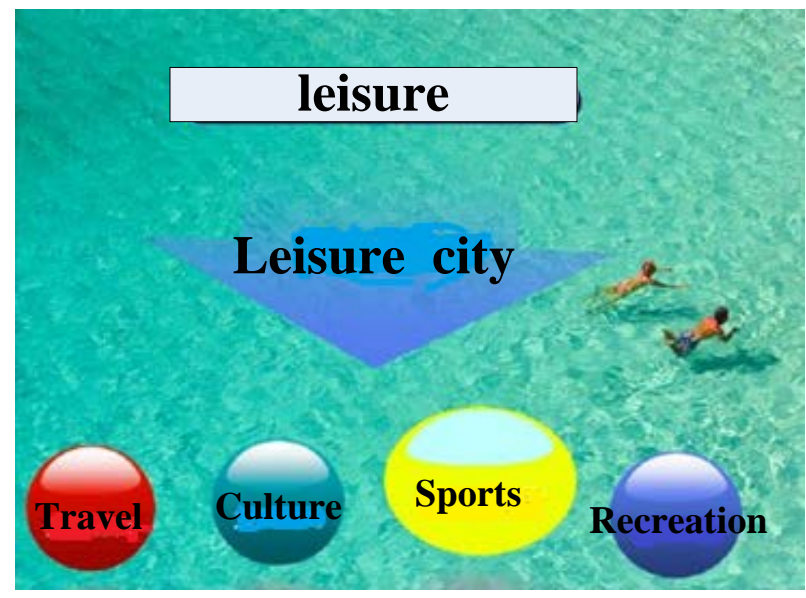

Fig. 1.The type of leisure urban development

The sports and leisure urban is the main theme of future city development. With the gradual improvement in the economic development of life, people's consumption concept of civilization began to pursue the health and quality of life "have more income and leisure time urban residents, after the illness started to pay attention not only care about their own bodies before, but advocating spend money on health, invest in fitness, health, entertainment, sports consumption is characterized 
by residents increased cultural, entertainment, sports, fitness and tourism spending, expand service consumption. First time the sports consumption as an important consumer items, thus in order to expand domestic demand and stimulate economic growth pioneering a new field.

Sports and leisure as a city location theme of the city, which takes the difference of the road, is undoubtedly the best choice to create urban values, theme-oriented urban leisure city, without a doubt is the most innovative and able to play to make the consideration of maximizing endowments the lowest, most economical and sustainable development path. Thus, sports city and people-oriented connotation main innovation in the future to enhance the sustainable competitiveness of the city process, seize the opportunities, has first-mover advantage. It is a city livable and recreational functions of unity, creating urban differences in personality, grew up in the city is an important stage of development.

\section{Construction of Sports Leisure Industry}

Hangzhou Fu yang City, which is both endowed this mountain beauty, but also with the show River City small city, with its unique concept of sports and leisure, becoming the first "Chinese sports and leisure city" reputation of the city. Our sports and leisure cities unveiled as a new chapter in urban planning. A number of other cities follow the trend and vigorously promote the plan of the sports leisure industry. In order to achieve this strategic goal, the following aspects should be actively useful [5]. Fig.2 shows the construction of sports leisure industry.

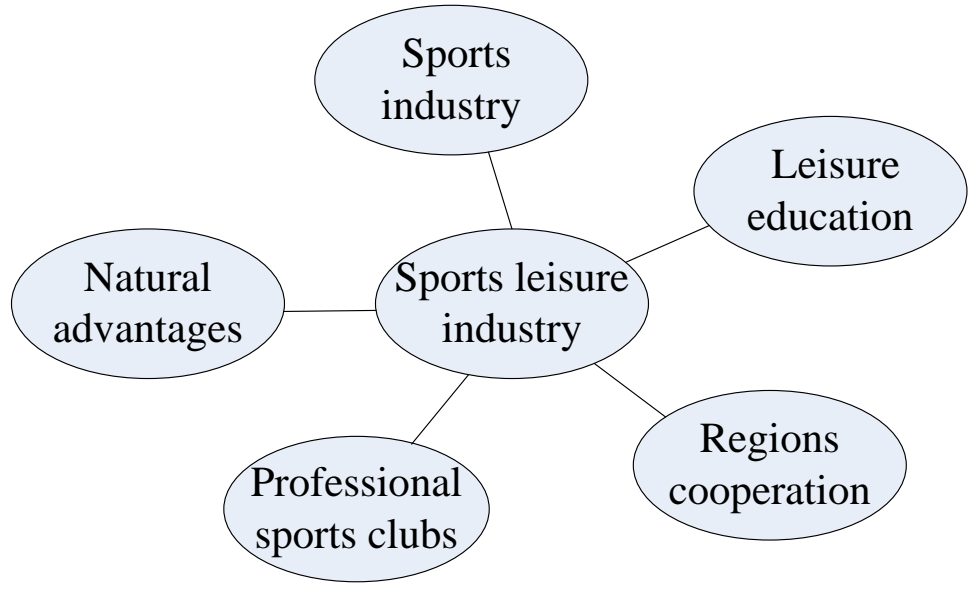

Fig. 2 The construction of sports leisure industry

In the construction of sports and leisure the city, we should give full play to the natural, geographical and regional advantages, sports departments should actively intervene to extend the scope of sports and leisure elements, the sea, beaches, parks and other leisure elements, sports should actively participate in fighting against these ownership and use of scarce resources. Sports and leisure elements so broad, and actively expand the sports and leisure elements in various fields. The relevant departments should actively with tourism, culture and other relevant departments to absorb learn from their experience in development efforts to promote sports and leisure and tourism, cultural festivals, marriage of new technology, to inject new vitality into the movement, speed sports and leisure industries across development. We should try to win the support of the government, through the development of sports and leisure sports and leisure industry policy and strategic development plan of the city, from urban planning to actively promote the strategic level, to guide the development of sports and leisure industries. For the implementation of the plan has to be active or planned projects, and gradually refined and improved self in action.

We should encourage the establishment of a steady professional sports clubs, and actively promote such professional societies, associations established to encourage market-oriented operation, self-financing, increased integration with the international, collaborative development in the information and projects. Some clubs have been mature, which can actively promote the establishment of the sports and leisure through the exchange of experience, knowledge, transfer of assets and other means. By development of leisure education, we can speed up the training of 
sports and leisure professionals. In the community, we can establish Leisure education by family and kindergartens, schools, institutions, social organizations and welfare agencies system. At the same time, we should develop and implement national public leisure education programs, and set up a special financial resource for the implementation of a national public education program of leisure, improvement and impact assessment [6].

The construction of new urbanization needs the establishment of large sports circle to strengthen industrial cooperation between regions, which should give full play to the port, trading above advantages, and actively promote the construction of both ends of the industry, the construction of the headquarters base. The enterprises need to build the end of the main structure, brands and services to promote the modernization of sports and leisure industry development

\section{Conclusions}

By the social development, the human has entered the era of leisure. There is no doubt that the sports leisure as an important factor to support outbreak of leisure time and as a high-level stage of city development for the direction of economy in the future. As a result of its rich intension and characteristic, new requirements are put forward for the urbanization. The theme of vision of scientific development is overall plans, so there are many new requirements for the urbanization. New pattern urbanization has a great many fresh traits such as urban-rural comprehensive development, intensive development, environmental amenity, social harmony, distinguishing feature, ecological sustainment and so on. We try to make best use of sports industry and other industries related to comprehensively promote industrial development, and achieve the new round of economic, growth shape with distinctive features of the economic.

\section{References}

[1] Henderson J V. The Effect of Urban Concentration on Economic Growth. NBER working paper (2000), p. 126-158.

[2] Terry Robertson. Foundations of therapeutic; recreation. Champion, IL: Human Kinetics, (2007).

[3] Ransom J K, Paudyal K, Adhikari K. Adoption of improved maize varieties in the hills of Nepal. Agricultural Economies, 29 (3) (2003), p. 299-305.

[4] Andrew Smith. REIMAGING THE CITY The Value of Sport Initiatives. Annals of Tourism Research, 32(1) (2005), p. 217-236.

[5] Joshua Wilson, Dawn Thilmany. Golfers in Colorado: The Role of Golf in Recreational and Tourism Lifestyles and Expenditures. Journal of Travel \& Tourism Marketing, 20 (3/4) (2006), p. 127-144.

[6] Mu-Yong Lee. The Place Marketing Strategy and the Cultural Politics of Space: A Case Study of the Club Cultures at the Hong-Dae area in Seoul. Seoul: Department of Geography of Seoul National University, (2003). 